\title{
Enhancement of Liver Toxicity on Diabetes Mellitus by a Universal Chemical Pollutant (Acrylonitrile) in Rats
}

\author{
Sameer E. Alharthi, PhD \\ Department of Pharmacology, Faculty of Medicine, King Abdulaziz University \\ Jeddah, Saudi Arabia
}

\section{Correspondence}

Dr. Sameer E. Alharthi

P.O. Box 80215, Jeddah 21589

Saudi Arabia

e-M: salharthe@kau.edu.sa

Submission: 24 Nov. 2019

Accepted: $\quad 09$ Dec. 2019

\section{Citation}

Alharthi SE. Enhancement of liver toxicity on diabetes mellitus by a universal chemical pollutant (acrylonitrile) in rats. JKAU Med Sci 2019; 26 (2): 9-17. DOI: 10.4197/Med. 26-2.2

Copyright: @The Author(s), YEAR. Publisher. The Journal of King Abdualziz University - Medical Sciences is an Official Publication of "King Abdulaziz University". It is an open-access article distributed under the terms of the Creative Commons Attribution Non-Commercial License, which permit unrestricted non-commercial use, distribution, and reproduction in any medium, provided the original work is properly cited.

\begin{abstract}
The present study was designed to investigate potential liver damage due to acrylonitrile in Streptozotocin induced diabetes in rats. Twentyfour rats were divided into 4 treatment groups. Nondiabetic control rat receiving distilled water, non-diabetic rat receiving acrylonitrile aqueous solution ( $10 \mathrm{mg} / \mathrm{kg} /$ day), diabetic control rat receiving distilled water and diabetic rat receiving acrylonitrile aqueous solution. All groups received the treatment for 4 weeks. The animals were assessed for hepatoxicity markers in serum, oxidative stress markers, CYP2E1 activity and cyanide formation in tissues. Acrylonitrile significantly elevated serum aminotransferase, alanine aminotransferase, total bilirubin levels, triglycerides and total cholesterol in diabetic groups as compared to normal control group. Antioxidant markers like glutathione showed significant decline while a significant increase in malondialdehyde, superoxide dismutase and catalase in diabetic rats treated with acrylonitrile. CYP2E1 activity was observed in acrylonitrile - exposed nondiabetic and diabetic groups as compared to control. Cyanide formation was raised in both the nondiabetic and diabetic groups as compared to control group. Acrylonitriles can produce acute hepatic injury, induction of diabetes mellitus type ll, and accomplish the CYP2E1 enzyme which sequentially leads to generation of oxidative stress and its metabolic product-cyanide that may potentiate the oxidative stress posing more deleterious effect.
\end{abstract}

\section{Keywords}

Acrylonitrile; Streptozotocin; Diabetes Type 2; Cytochrome P450 2E1; Cyanide; Liver toxicity

\section{Introduction}

crylonitrile (ACN) is extensively utilized in the manufacturing of several industrial products like nitrile rubbers, plastics, synthetic fibers and fumigants of insect killers for grain ${ }^{[1]}$. In addition, it also finds use as an intermediate in the synthesis of antioxidants, surface coatings, adhesives, and dyes ${ }^{[1]}$. Acrylonitrile is also used in the manufacturing of dialysis tubing possessing high permeability ${ }^{[2]}$, and cigarette smoke ${ }^{[3]}$. Metabolism of ACN in human is through two main metabolic pathways (i) Glutathione conjugation and (ii) oxidation by Cytochrome P450. The conjugation of ACN with glutathione leads mainly to produce 
2-cyanoethyl mercapropuric acid ( $\mathrm{N}$-acetyl-S-2-cyano ethyl cysteine $\mathrm{e}^{[4,5]}$. Cytochrome P-450 oxidation yield 2-cyanoethyleneoxideandcyanide (CN) that undergoes conjugation with reduced glutathione to yield multiple metabolites including cyanide and thiocyanate ${ }^{[6]}$.

It was observed that ACN induced acute toxicity in rats is characterized by damage to the tissues of vital organs which includes liver, lung, brain and kidney ${ }^{[7-12]}$, stomach $^{[13]}$, and lysis of adrenal cortex ${ }^{[14]}$.

One of the hallmarks of diabetes is the requirement of multiple medications with longterm administration which may consequently lead to unavoidable complications $s^{[, 15]}$. A recent study highlighted that in drug induced diabetes in rats as well as normal rats, the level of enzymes responsible for hepatic drug metabolism was reduced. The decreased enzymes included glutathione reductase, glutathione peroxidase, p-nitrophenol glucuronosyl transferase, arylsulphotransferase I and II ${ }^{[16]}$.

In contrast, Sindhu et al. ${ }^{[17]}$ studied the expression of major isozymes of CYP450 in Streptozotocin (STZ) induced diabetes with simultaneous treatment with insulin. They reported upregulation of microsomal activity of CYP1B, CYP1A, heme oxygenase (HO)-2 proteins and CYP1A2-dependent 7-ethoxyresorufin O-demethylase (EROD) in the diabetic rats. The expression of CYP1A, CYP1B1 and HO-2 had been improved by insulin and there was a noticeable induction in CYP2B1 and 2E1 proteins in diabetic animals. Treatment with insulin caused total and partial restorations of CYP2E1 and CYP2B1 proteins, respectively. Similarly, insulin could in part improve CYP2C11 protein while diabetic state decreased it by $>99 \%$. The decisive disclosure of this study is that overall changes in the expression of different isozymes of CYP450 exist in diabetic rats which can be evidently ameliorated by insulin therapy ${ }^{[18,19]}$. This study was performed to assess the potential liver damaging effect of ACN and enzyme induction per se in diabetes mellitus (DM) leading to supplementary deleterious effect in the presence of DM.

\section{Materials and Methods}

\section{Animals}

Male Sprague Dawley rats weighing 150-200 g were obtained from the animal facility of King Fahd Medical Research Center, King Abdulaziz University,
Jeddah, Saudi Arabia. The animals were provided with standard pellet diet and water ad libitum. They were kept at typical conditions (room temperature of 25 $\pm 2^{\circ} \mathrm{C}, 45-55 \%$ relative humidity and $12 \mathrm{~h}$ dark/light cycle). Procedures involving animals and their care were conducted in conformity with the institutional guidelines of King Abdulaziz University, Jeddah, Saudi Arabia.

\section{Induction of Diabetes}

Type 2 diabetes was induced by injecting freshly prepared STZ, dissolved in cold citrate buffer $(0.1 \mathrm{M})$, $\mathrm{pH} 4.5$ at dose $(35 \mathrm{mg} / \mathrm{kg})$ as a single intraperitoneal injection to overnight-fasted rats. The rats were tested for successful induction of diabetes after 2,5 and 8 days of STZ injection by determining fasting blood glucose levels. Rats with blood glucose levels ranging between $250-350 \mathrm{mg} / \mathrm{dl}$ were selected ${ }^{[18]}$. Fasting blood samples were collected from the tail vein of the overnight (12$15 \mathrm{~h}$ ) fasting rats. The blood glucose level was analyzed using One Touch Ultra (LifeScan/Johnson \& Johnson, Milpitas, CA, USA).

\section{Animal Treatments}

Twenty-four rats were divided into four groups (six animals per group). Groups 1 and 2 were normal healthy animals while groups 3 and 4 were diabetic rats. Briefly, group 1 served as negative control receiving only distilled water for 4 weeks. Group 2 was administered aqueous solution of ACN orally $(10 \mathrm{mg} /$ $\mathrm{kg} / \mathrm{d}$ ) for 4 weeks. This dose represents one tenth of oral LD50 of ACN in rats ${ }^{[19]}$. Group 3 served as a diabetic group receiving only distilled water for 4 weeks. Group 4 served as diabetic group exposed to $\mathrm{ACN}$ under the same conditions as group 2 (10 mg/kg/d for 4 weeks).

\section{Preparation of Tissue and Serum Samples}

Blood samples were collected from the retro-orbital plexus followed by centrifugation at $3000 \mathrm{~g}$ for $15 \mathrm{~min}$ for serum separation ${ }^{[19]}$. The serum was stored at $-80^{\circ} \mathrm{C}$ until the assessment of hepatotoxicity markers. Rats were sacrificed and liver tissues were dissected and homogenized at 1:5 (w/v) with the phosphate-buffered saline (PBS) pH 7.4.

\section{Evaluation of Hepatotoxicity Markers}

Serum aspartate aminotransferase (AST), alanine aminotransferase (ALT), total cholesterol, triglycerides 
and total bilirubin were assessed colorimetrically using commercially available kits (Spectrum Diagnostics, Cairo, Egypt). Liver index was calculated as liver weight/ body weight X 100 .

\section{Assessment of Oxidative Stress Markers}

Hepatic tissues homogenate was used for determination of lipid peroxides by assessing the level of thiobarbituric acid reactive substances (TBARS) expressed as nmol malondialdehyde (MDA)/gram tissue. Reduced glutathione (GSH) level and superoxide dismutase (SOD) and catalase (CAT) activities were determined in liver tissues using commercially available kits (Biodiagnostics, Cairo, Egypt) ${ }^{[18]}$. The protein content in the hepatic homogenates was determined according to the method of Lowry et al. ${ }^{[19,20]}$ using bovine serum albumin as a standard.

\section{Cytochrome P450 2E1 (CYP2E1) Activity}

Colorimetric assay was used to measure CYP2E1 activity through hydroxylation of p-nitrophenol according to Chang et al. ${ }^{[21]}$. Briefly the assay monitors the formation of "p-nitrocatechol" from "p-nitrophenol" due to the enzymatic action of CYP2E1. Then, the product "p-nitrocatechol" was acidified by trichloro acetic acid followed by neutralization with $2 \mathrm{~N} \mathrm{NaOH}$ and then assessed colorimetrically at wavelength $535 \mathrm{~nm}$.

\section{Cyanide Determination}

$\mathrm{CN}^{-}$concentration in the hepatic homogenates (10\% $\mathrm{w} / \mathrm{v}$ in PBS) was determined electrochemically as described by Abreu and Ahmed ${ }^{[22]}$. Briefly, $2 \mathrm{~mL}$ of the homogenate was added to $2 \mathrm{~mL} 4 \mathrm{~N} \mathrm{H}_{2} \mathrm{SO}_{4}$ contained in the outer chamber of a Conway microdiffusion cell (Thomas Scientific, Swedesboro, NJ USA). The inner chamber contained $2 \mathrm{~mL} 0.1 \mathrm{~N} \mathrm{NaOH}$. Silicone grease was used for sealing the cells with a glass cover and rotating at $0.8 \times \mathrm{g}$ for $2 \mathrm{~h}$. In the inner chamber of the Conway microdiffusion cell Silver sulfide electrode model $9416 \mathrm{BN}$ and double junction reference electrode model 9202 (Orion Research Inc., Cambridge, MA, USA) were placed to which $50 \mu \mathrm{L} \mathrm{KAg}(\mathrm{CN})_{2}$ indicator solution was added. The indicator solution was prepared by adding $1.25 \mathrm{M} \mathrm{Na}_{2} \mathrm{HPO}_{4^{\prime}} 0.55 \mathrm{M} \mathrm{NaOH}$, and $0.46 \mathrm{mM}$ $\mathrm{KAg}(\mathrm{CN})_{2}$ to make up final volume of $100 \mathrm{~mL}$. Millivolts were determined using a Hanna $\mathrm{pH}$ meter (model 8417). Serially diluted standards of $\mathrm{NaCN}$ were used to construct the standard curve. The $\mathrm{CN}^{-}$content of samples was determined from this standard curve.

\section{Statistical Analysis}

The results were expressed as mean \pm standard error of measurement and statistically analyzed using oneway analysis of variance (ANOVA) followed by student Tukey-Kramer post hoc test. $\mathrm{P}$ values $\leq 0.05$ were considered significant. The percentage of change was calculated as follows:

$$
\text { Percentage Change }=(\text { treated } \text { control }) /(\text { control })
$$
$\times 100$.

\section{Results}

\section{Hepatotoxicity Markers}

As shown in Figure $1 A$, normal rats exposed to ACN have shown more than a 3-fold increase in serum AST level, compared to the control group. The same effect was obtained in diabetic rats, where AST level was elevated by a comparable extent. However, when diabetic rats were exposed to $\mathrm{ACN}$, the combined effect was greatly higher, resulting in about a 5 -fold increase in serum AST level, compared to the control group. Interestingly, exposure of diabetic group to ACN significantly elevated AST by about $57 \%$ and $67 \%$, when compared to ACN-exposed nondiabetic and diabetic groups, respectively. It is worth noting that analogous patterns of effects were observed for ALT and total bilirubin levels. There were significant and comparable increases in their serum levels in $\mathrm{ACN}$-exposed and diabetic rats, compared to the control group. Additionally, exposing diabetic animals to ACN markedly increased serum levels of ALT and total bilirubin, compared to all other groups, as shown in Figure 1B, and 1C, respectively.

Regarding serum triglycerides level, ACN-exposed nondiabetic exposed animals failed to show any significant change when compared to the control group, as shown in Figure 1D. However, diabetic rats have shown a significant rise of serum triglycerides by about $42 \%$, compared to the control. This effect was further magnified when diabetic animals were exposed to $A C N$, where serum triglycerides level was significantly elevated by about $60 \%$ compared to the control and $13.2 \%$ compared to the diabetes-alone group. A similar pattern of observations was obtained 


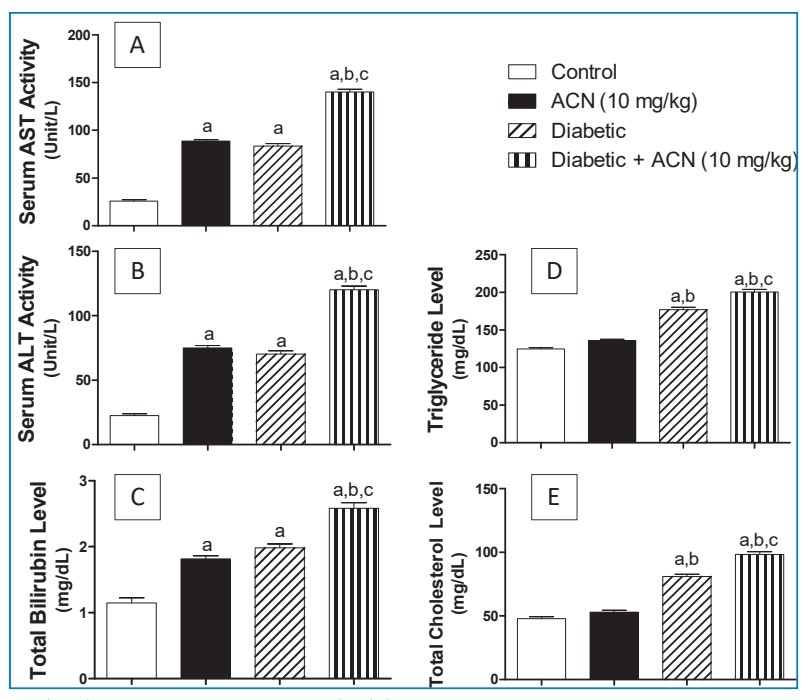

Each value represents mean \pm Standard deviation $n=6$

Statistical analysis was carried out using ANOVA followed by student Tukey-Kramer post hoc test.

aSignificantly different from the control at $p<0.05$

bSignificantly different from acrylonitrile-exposed nondiabetic group at $p<0.05$ csignificantly different from the diabetic group at $p<0.05$

Figure 1. Effects of acrylonitrile and diabetes on serum hepatotoxicity markers: aspartate aminotransferase (Panel A), ALT (Panel B), total bilirubin (Panel C), triglycerides (Panel D) and total cholesterol (Panel E) in normal and STZinduced diabetic rats. with total cholesterol level. As detected in Figure 1E, no change was observed in ACN-exposed nondiabetic group, with a significant elevation in diabetic animals by $69 \%$, compared to the control group. Importantly, diabetic animals exposed to ACN have shown more than a 2-fold increase of serum level of total cholesterol.

\section{Oxidative Stress Markers}

Oxidative status was evaluated by measuring the hepatic content of GSH as an antioxidant marker and MDA concentration as a lipid peroxidation marker, in addition to the enzymatic activities of two antioxidant enzymes: SOD and CAT, in hepatic tissue homogenates. As shown in Figure 2A, ACN caused a significant depletion of GSH by about $50 \%$ compared to the control group. Diabetes itself induced oxidative imbalance as manifested by a significant reduction of GSH content by about $27 \%$ compared to the control. However, when diabetes was combined with ACN exposure, the net effect was markedly significant from all tested groups, as GSH was reduced by about $60 \%$ compared to the control. These observations were further reinforced by measuring MDA as lipid peroxidation marker, as demonstrated in Figure 2B. Animals exposed to ACN have significantly increased MDA concentration to almost two times the control value. In diabetic rats, MDA concentration was elevated by about $60 \%$ when compared to the control group. However, exposure of diabetic rats to $A C N$ resulted in an amplified effect on MDA concentration that was significantly higher than

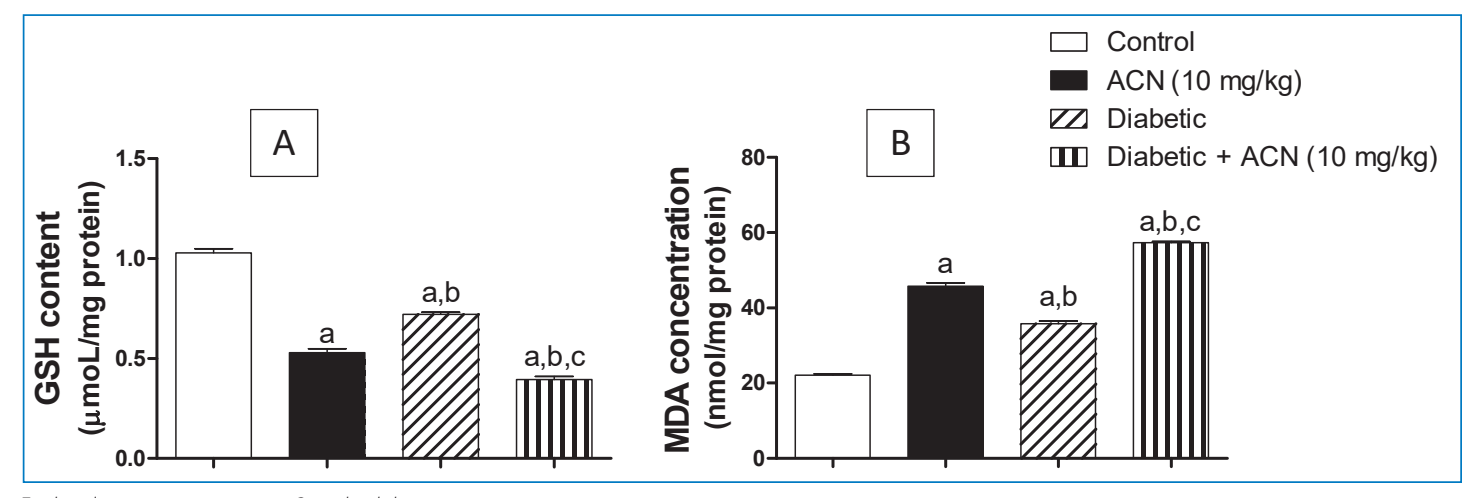

\footnotetext{
Each value represents mean \pm Standard deviation

$n=6$

Statistical analysis was carried out using ANOVA followed by student Tukey-Kramer

post hoc test.

asignificantly different from the control at $p<0.05$

bSignificantly different from acrylonitrile-exposed nondiabetic group at $p<0.05$

cSignificantly different from the diabetic group at $p<0.05$
}

Figure 2. Effects of acrylonitrile and diabetes on oxidative stress markers: reduced glutathione (Panel A) and lipid peroxidation malondialdehyde (Panel B) in hepatic tissue homogenate of normal and STZ-induced diabetic rats. 


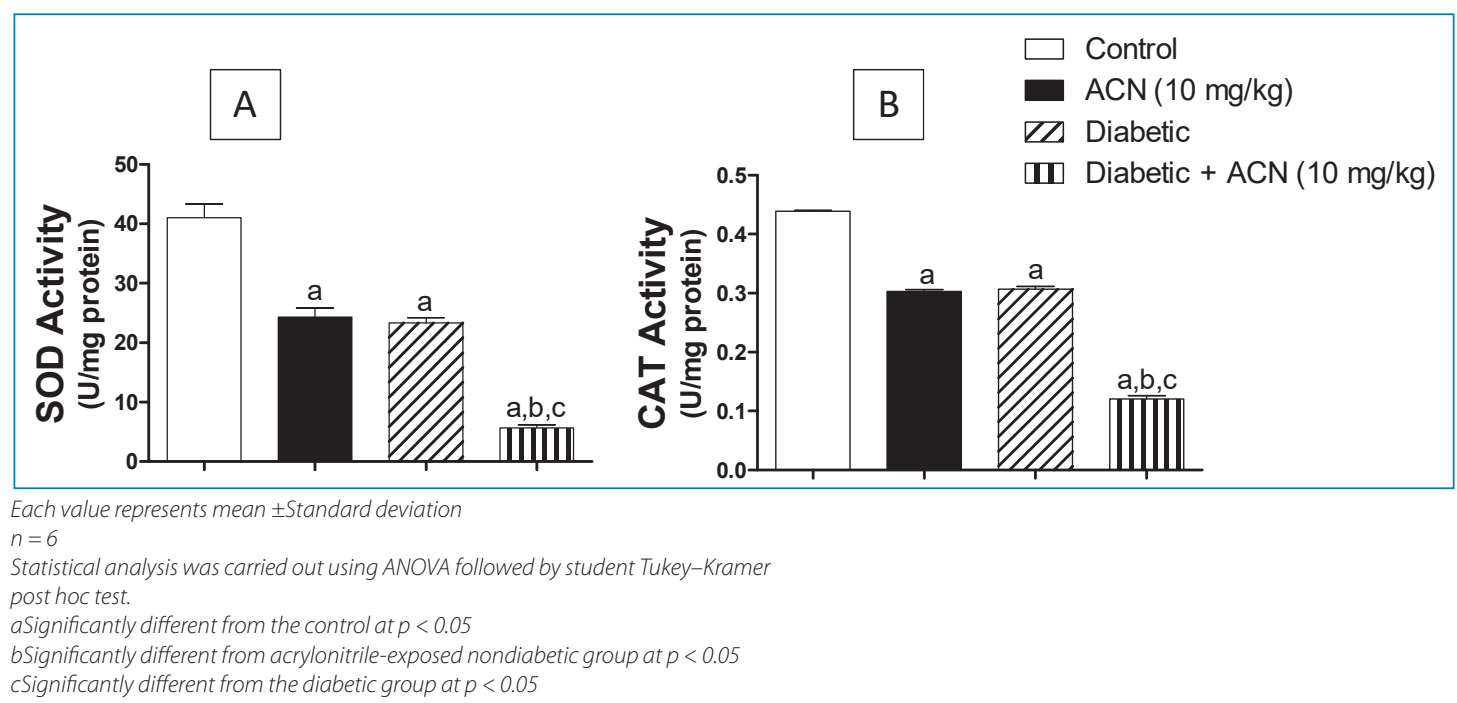

Figure 3. Effects of acrylonitrile and diabetes on antioxidant enzyme activities: superoxide dismutase "SOD" (Panel A) and catalase "CAT" (Panel B) in hepatic tissue homogenate of normal and STZ-induced diabetic rats.

all other groups (control, ACN-exposed nondiabetic and diabetic animals).

Concerning SOD enzymatic activity, exposure of normal animals to ACN significantly decreased SOD activity by about $41 \%$ compared to the control, as shown in Figure 3A. A similar effect was detected in the diabetic group, where SOD activity was dropped by an analogous degree. However, the net effect of diabetes and $\mathrm{ACN}$ exposure was much more significant than all other groups; being able to reduce SOD activity to about $14 \%$ of the control value. Parallel to these findings, CAT activity was decreased in a comparable pattern, as shown in Figure 3B. Acrylonitrile-exposed nondiabetic and diabetic groups have demonstrated about a 30\% reduction compared to the control group, while in diabetic animals exposed to $\mathrm{ACN}$, a significant decrease of CAT activity by about $72 \%$ of the control value was observed.

\section{Cytochrome P4502E1 (CYP2E1) Activity}

As shown in Figure 4, CYP2E1 activity was significantly increased by $29 \%$ and $20 \%$ in ACN-exposed nondiabetic and diabetic groups, respectively, compared to the control. No significant difference was detected between these two groups; ACN-exposed non-diabetic and diabetics. It is worth mentioning that exposure to ACN in diabetic rats markedly activated CYP2E1 by about $82 \%$ compared to the control group. Interestingly, this effect was also significant in comparison to the other groups (ACN-exposed non-diabetic and diabetic

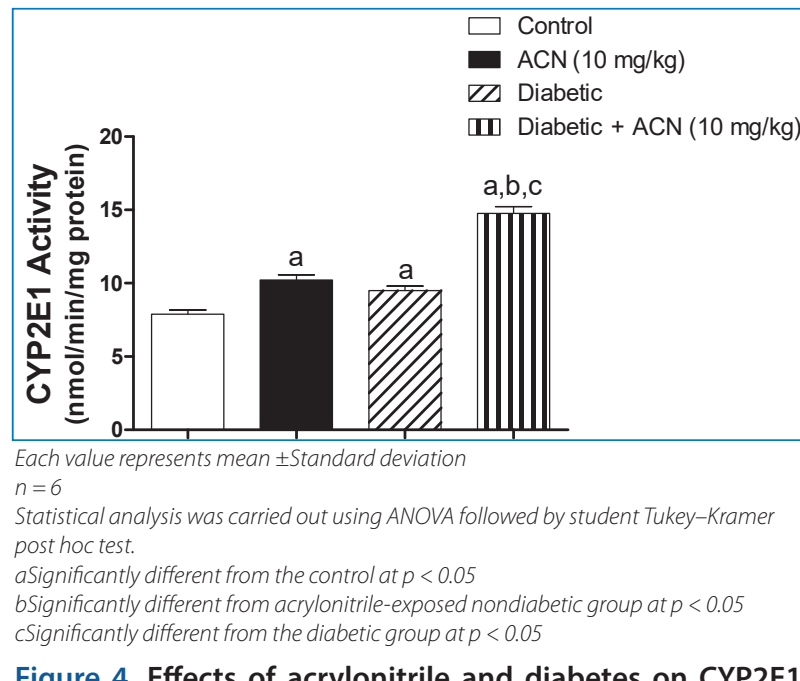

Figure 4. Effects of acrylonitrile and diabetes on CYP2E1 activity in hepatic tissue homogenate of normal and STZinduced diabetic rats.

groups).

\section{Cyanide Formation}

Cyanide concentration in the hepatic homogenates was assayed electrochemically and results were illustrated in Figure 5 . In the absence of ACN, cyanide formation was negligible in both the control and diabetic groups. As a result of ACN exposure in nondiabetic rats, its metabolic product - cyanide - was produced in a significant amount ( $>20$-fold), compared to the control. Moreover, exposure to ACN in diabetic 


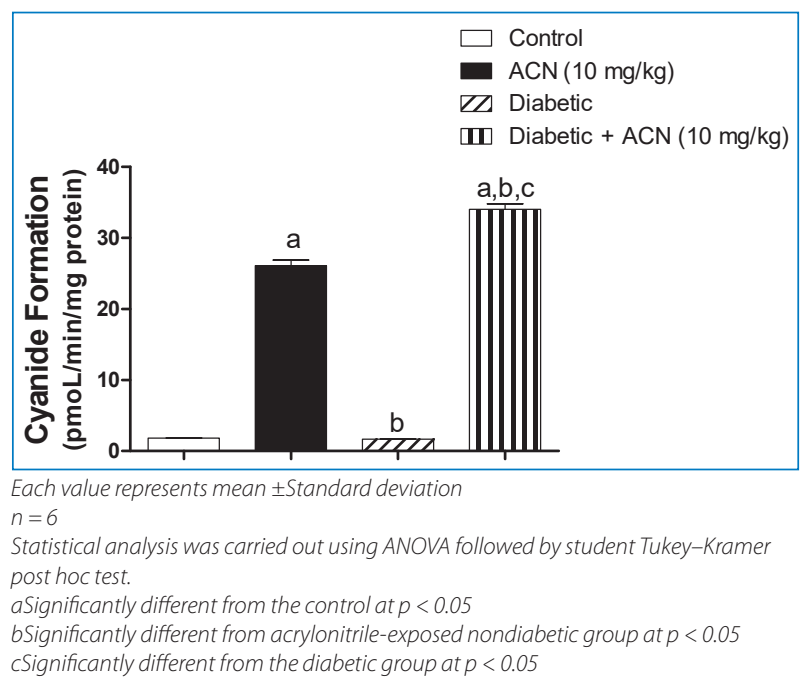

Figure 5. Effects of acrylonitrile and diabetes on cyanide production in hepatic tissue homogenate of normal and STZ-induced diabetic rats.

rats obviously caused more than a 30 -fold increase in cyanide production, compared to the control group, an effect that was also significant when compared to ACNexposed non-diabetic rats.

\section{Discussion}

Several worldwide research studies have revealed that environmental pollutants potentially act as a contributing determinant for DM. Chronic exposure to the pesticides and herbicides often creates disturbance in glucose metabolism and is also capable of inducing insulin resistance ${ }^{[23,24]}$. Moreover, organic pollutants are lipophilic in nature and the likelihood of obesity potentiates the ability of the body to store these toxic chemicals which in turn are proficient in inducing insulin resistance as well as DM type II (DM2) in a dose and perhaps time dependent manner ${ }^{[25,26]}$.

The results of this study decisively illustrate that ACN alone quite significantly produces acute injury to hepatocytes of rats as revealed by an increased level of not only liver enzymes but also the serum levels of total cholesterol and triglycerides. It is noteworthy that these parameters were also augmented in a similar manner in drug induced diabetic rats, thus confirming the detrimental effect of both $\mathrm{ACN}$ and DM2 in producing acute hepatotoxicity. Seemingly, diabetic animals exposed to ACN have shown a marked increase in all the parameters of liver injury in comparison to ACN alone treated rats and untreated drug induced diabetic rats, thus confirming the finding so for the relevant studies $^{[22-26]}$.

In addition, a remarkable feature in DM2 is enhancement of oxidative stress which is in turn responsible for several chronic degenerative complications. The prime objective of the treatment of DM is to prevent several chronic degenerative complications which is basically due to the phenomenon of oxidative stress which in turn occurs as a result of excessive formation of free radicals sufficient enough to overcome the detoxification capacity of the cellular antioxidant system ${ }^{[27,28]}$. A well-established fact in DM is the vulnerability of hyperglycemia as a driving force for the development of well-known diabetic complications $^{[29]}$. This study remarkably revealed the substantial effect of ACN as well as drug induced DM2 on the parameters of both enzymatic antioxidants which includes depressant activity on the hepatic content of GSH as an antioxidant marker and significant amplification of lipid peroxidation MDA and similar a depressant effect on non-enzymatic antioxidants such as SOD enzymatic activity and CAT activity on both hepatic tissue homogenate of normal and STZinduced diabetic rats.. Furthermore, these observations were enforced by a marked increase in MDA as lipid peroxidation marker. However, a concomitant effect was revealed on non-enzymatic antioxidants i.e., SOD and CAT. These results are fairly consistent with the observations revealed in several studies ${ }^{[27,28]}$.

Several studies demonstrated significant elevation of CYP2E1 enzymes in different liver disorders and $\mathrm{DM}^{[14,30,31]}$. In addition it was also demonstrated that the expression of CYP1A2 and CYP2E1 was observed to be significantly higher in diabetic rats in comparison to normal rats ${ }^{[32,33]}$.

In in this current study it was noteworthy that CYP2E1 activity was appreciably augmented in both ACN-exposed nondiabetic and diabetic groups, respectively, compared to the control group. However, exposure to ACN in diabetic rats markedly amplified the levels of CYP2E1 enzyme, which has directed the observation of potentiation of harmful effect of ACN in DM.

Finally, it is pertinent to emphasize the consequence of $\mathrm{ACN}$ on the hepatic homogenates in this present study, which has revealed negligible formation of cyanide in the absence of ACN in both the control and diabetic groups. However, in nondiabetic 
rats significant enhancement of cyanide was observed in comparison to the control group. Likewise, exposure to ACN in diabetic rats obviously caused further augmentation in cyanide production, compared to the control group, an effect that was also significant in comparison to $\mathrm{ACN}$-exposed nondiabetic rats. These findings are splendidly sustained by the findings of several studies illustrating the oxidation of ACN by CYP2E1, which subsequently gets converted to 2-cyanoethyleneoxide (CEO), which is well known as a reactive and a relatively long-lived epoxide ${ }^{[34]}$. CEO gets in turn metabolized leading to the release of $\mathrm{CN}$ reactive and a relatively long-lived epoxide ${ }^{[38]}$.

Interestingly, the present study results of augmentation of cyanide production by $\mathrm{ACN}$ is further authenticated by the studies demonstrating that $\mathrm{CN}$ might enhance $\mathrm{ACN}$ induced oxidative stress by increasing hydroperoxide generation and lipid peroxidation $^{[35]}$.

\section{Conclusion}

Acrylonitrile, a well-known industrial pollutant, is capable of producing acute hepatic injury as well as induction of DM2. In addition, it can also saturation of the CYP2E1 enzyme which sequentially leads to generation of oxidative stress and its metabolic product, cyanide, that poses additional deleterious effects due to potentiation of the oxidative stress.

\section{Conflict of Interest}

The author has no conflict of interest regarding the publication of this paper.

\section{Disclosure}

The author did not receive any type of commercial support for this study.

\section{Ethical Approval}

Obtained by the Bioethical Research Unit of Faculty of Medicine, King Abdulaziz University.

\section{Acknowledgement}

The author would like to thank Dr. Ahmed Esmat, Dr. Lateef Khan and Dr. Shahid Karim (Department of Pharmacology, Faculty of Medicine, King Abdulaziz University) for all the assistance provided to undertake the study.

\section{References}

[1] Pilon D, Roberts $A E$, Rickert DE. Effect of glutathione depletion on the irreversible association of acrylonitrile with tissue macromolecules after oral administration to rats. Toxicol Appl Pharmacol 1998; 95(2): 311-20.

[2] Ward RA, Schaefer RM, Falkenhagen D, Joshua MS, Heidland A, Klinkmann H, Gurland HJ. Biocompatibility of a new high permeability modified cellulose membrane for haemodialysis. Nephrol Dial Transplant 1993; 8(1): 47-53.

[3] Laugesen M, Fowles J. Scope for regulation of cigarette smoke toxicity according to brand differences in published toxicant emissions. N Z Med J 2005; 118(1213): U1401.

[4] Fennell TR, Kedderis GL, Sumner SC. Urinary metabolites of (1,2,3-13C) acrylonitrile in rats and mice detected by ${ }^{13} \mathrm{C}$ nuclear magnetic resonance spectroscopy. Chem Res Toxicol 1991; 4(6): 678-687.

[5] International Programme of Chemical Safety IPCS. Acrylonitrile. Concise International Chemical Assessment Document 39. 2002, WHO: Geneva.

[6] Guengerich, FP, Geiger LE, Hogy LL, Wright PL. In Vitro metabolism of Acrylonitrile to 2-Cyanoethylene Oxide, reaction with glutathione, and irreversible binding to proteins and nucleic acids. Cancer Res 1981; 41(12 Pt 1): 4925-4933.

[7] Ahmed AE, Abdel-Aziz AH, Abdel-Rahman SZ, Haque AK, Nouraldeen AM, Shouman SA. Pulmonary toxicity of acrylonitrile: covalent interaction and effect on replicative and unscheduled DNA synthesis in the lung. Toxicol 1992; 76(1): 1-14.

[8] Døssing M, Ranek L. Isolated liver damage in chemical workers. Br J Ind Med 1984; 41(1): 142-144.

[9] Karami S, Boffetta P, Brennan P, Stewart PA, Zaridze D, Matveev $V$, Janout $V$, Kollarova $H$, Bencko V, Navratilova M, Szeszenia-Dabrowska N, Mates D, Gromiec JP, Sobotka R, Chow WH, Rothman N, Moore LE. Renal cancer risk and occupational exposure to polycyclic aromatic hydrocarbons and plastics. J Occup Environ Med 2011; 53(2): 218-223.

[10] Li F, Dong Y, Lu R, Yang B, Wang S, Xing G, Jiang Y. Susceptibility to the acute toxicity of acrylonitrile in streptozotocin-induced diabetic rats: protective effect of phenethyl isothiocyanate, a phytochemical CYP2E1 inhibitor. Drug Chem Toxicol 2019: 1-10.

[11] Enongene EN, Sun PN, Mehta CS. Sodium thiosulphate protects against acrylonitrile-induced elevation of glial fibrillary acidic protein levels by replenishing glutathione. Environ Toxicol Pharmcol 2000; 8(2): 153-161.

[12] Esmat A, El-Demerdash, E, El-Mesallamy H, Abdel-Naim AB. Toxicity and oxidative stress of acrylonitrile in rat primary glial cells:preventive effects of $\mathrm{N}$-acetylccysteine. Toxicol Lett 2007; 171(13): 111-118. 
[13] Al-Abbasi FA. Acrylonitrile-induced gastric toxicity in rats: role of xanthine oxidase. Med Sci Monit 2012; 18(6): BR208-BR214.

[14] Szabo S, Hüttner I, Kovacs K, Horvath E, Szabo D, Horner $\mathrm{HC}$. Pathogenesis of experimental adrenal hemorrhagic necrosis ("apoplexy"): ultrastructural, biochemical, neuropharmacologic, and blood coagulation studies with acrylonitrile in the rat. Lab Invest 1980; 42(5): 533-546.

[15] Bigner DD, Bigner SH, Burger PC, Shelburne JD, Friedman HS. Primary brain tumours in fischer 344 rats chronically exposed to acrylonitrile in their drinking-water. Food Chem Toxicol 1986; 24(2): 129-137.

[16] Toda A, Eyanagi R, Saito H, Soeda S, Shimeno H, Moriyama $M$, Shigematsu $H$. Effects of experimental diabetes on hepatic drug metabolism in rats: the activities of flavincontaining monooxygenase, the phase II conjugation reactions and glutathione related enzymes. Res Commun Mol Pathol Pharmacol 2005; 117-118: 13-27.

[17] Sindhu RK, Koo JR, Sindhu KK, Ehdaie A, Farmand F, Roberts CK. Differential regulation of hepatic cytochrome p450 monooxygenases in streptozotocin-induced diabetic rats. Free Radic Res 2006; 40(9): 921-928.

[18] El-Sayed el-SM, Abo-Salem OM, Abd-Ellah MF, Abd-Alla GM. Hesperidin, an antioxidant flavonoid, prevents acrylonitrileinduced oxidative stress in rat brain. J Biochem Mol Toxicol 2008; 22(4): 268-273.

[19] LOWRY OH, ROSEBROUGH NJ, FARR AL, RANDALL RJ. Protein measurement with the Folin phenol reagent. J Biol Chem 1951: 193(1): 265-275.

[20] Yoshino G, Iwai M, Kazumi T, Matsushita M, Morita M, Matsuba K, Iwatani I, Baba S. Effect of dietary fructose on triglyceride turnover in streptozotocin-diabetic rats. Atherosclerosis 1989; 79(1): 41-46.

[21] Chang TK, Crespi CL, Waxman DJ. Spectrophotometric analysis of human CYP2E1-catalyzed p-nitrophenol hydroxylation. Methods Mol Biol 2006; 320: 127-131.

[22] Abreu ME, Ahmed AE. Metabolism of acrylonitrile to cyanide. In-Vitro studies. Drug Metab Dispos 1980; 8(6): 376-379.

[23] Lee DH, Lee IK, Song K, Steffes M, Toscano W, Baker BA, Jacobs DR Jr. A strong dose-response relation between serum concentrations of persistent organic pollutants and diabetes: results from the National Health and Examination Survey 1999-2002. Diabetes Care 2006; 29(7): 1638-1644.

[24] Lee DH, Lee IK, Jin SH, Steffes M, Jacobs DR Jr. Association between serum concentrations of persistent organic pollutants and insulin resistance among nondiabetic adults: results from the National Health and Nutrition Examination Survey 1999-2002. Diabetes Care 2007; 30(3): 622-628.

[25] Porta, M. Persistent organic pollutants and the burden of diabetes. Lancet 2006; 368(9535): 558-559.

[26] Lee DH, Jacobs DR Jr, Porta M. Could low-level background exposure to persistent organic pollutants contribute to the social burden of Type 2 diabetes? J Epidemiol Community Health 2006; 60(12): 1006-1008.

[27] Halliwell B. Free radicals and antioxidants - quo vadis? Trends Pharmacol Sci 2011; 32(3): 125-130.

[28] Kawahito S, Kitahata H, Oshita S. Problems associated with glucose toxicity: role of hyperglycemia-induced oxidative stress. World J Gastroenterol 2009; 15(33): 4137-4142.

[29] Weltman MD, Farrell GC, Hall P, Ingelman-Sundberg $M$, Liddle C. Hepatic Cytochrome P450 2E1 is increased in patients with nonalcoholic steatohepatitis. Hepatology 1998; 27(1): 128-133.

[30] Niemelä O, Parkkila S, Juvonen RO, Viitala K, Gelboin HV, Pasanen M. Cytochromes P4502a6, 2e1, and 3a and production of protein-aldehyde adducts in the liver of patients with alcoholic and non-alcoholic liver diseases. J Hepatol 2000; 33(6): 893-901.

[31] Kim YC, Lee AK, Lee JH, Lee I, Lee DC, Kim SH, Kim SG, Lee MG. Pharmacokinetics of theophylline in diabetes mellitus rats: induction of cyp1a2 and CYP2e1on1,3dimethyluricacid formation. Eur J Pharm Sci 2005; 26(1): 114-123.

[32] Li L, Zhang Y. [Changes of CYP2e1 activity in diabetic rat model.] Yao Xue Xue Bao 1998; 33(12): 891-895.

[33] Kedderis GL, Batra R, Turner MJ Jr. Conjugation of acrylonitrile and 2-cyanoethylene oxide with hepatic glutathione. Toxicol Appl Pharmacol 1995; 135(1): 9-17.

[34] Guangwei X, Rongzhu L, Wenrong X, Suhua W, Xiaowu Z, Shizhong W, Ye Z, Aschner M, Kulkarni SK, Bishnoi M. Curcumin pretreatment protects against acute acrylonitrile-induced oxidative damage in rats. Toxicology 2010; 267(1-3): 140-146.

[35] Zhang H, Kamendulis LM, Klaunig JE. Mechanisms for the induction of oxidative stress in Syrian hamster embryo cells by acrylonitrile. Toxicol Sci 2002; 67(2): 247-255. 


\title{
تعزيز سمية الكبا في داء السكري عن طريق ملوث كيميائي عالمي (أكريلونيتريل) في الفئران
}

\author{
سمير عيضة الحارثي \\ قسم علم الأدوية، كلبة الطب النب النب \\ جامعة الملاك عبدالعزبيز \\ جلة - المعلكة العربية السعودية
}

المستخلص. تم تصميم هذه الدر اسة للتحقيق في أضر ار الكبد المحتملة بسبب الأكريلونيتريل (CAN) في مرض فئ السكري

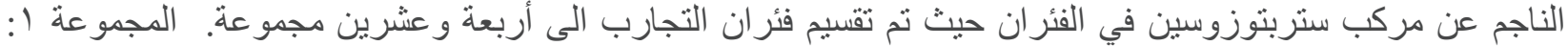

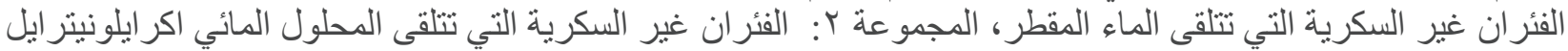

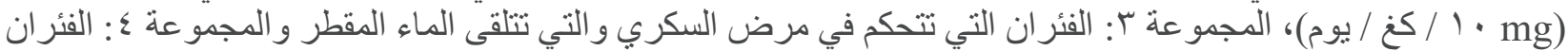

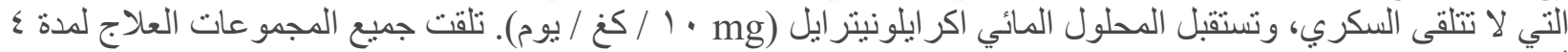

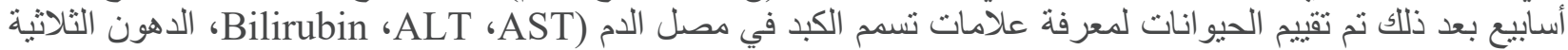

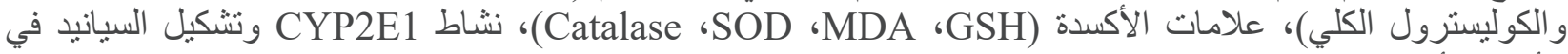

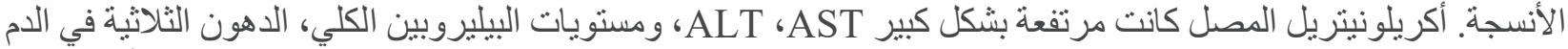

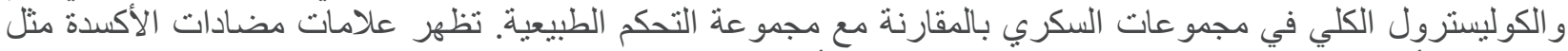

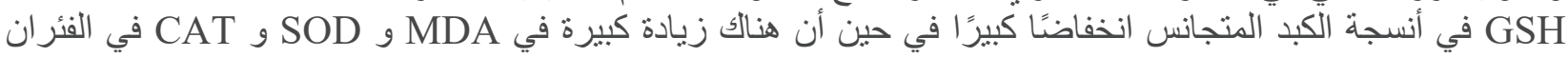

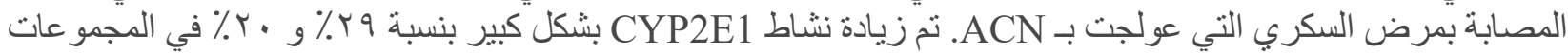

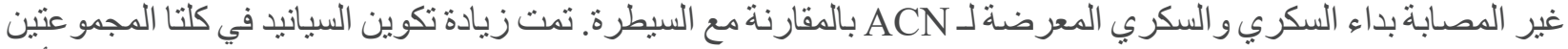

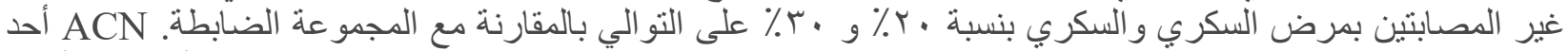

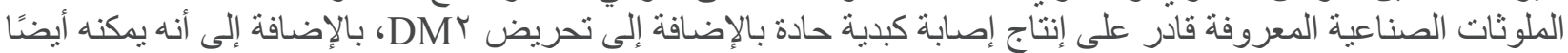

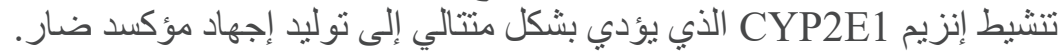

